\title{
Realistic demand and route choice of archives management in Colleges and universities in the information age
}

\author{
Jie Lin \\ School of Public Administration, South China University of Technology, Guangdong, Guangzhou \\ 510640, China \\ email: tkdjet@hotmail.com
}

Keywords: Archives management in colleges and universities; Information construction; Realistic demand; Path selection

\begin{abstract}
With the advent of the information age, the archives management in Colleges and universities is facing the challenge from the reality. College archives management is the most important part of the daily work in Colleges and universities, and it can measure the management level of colleges and universities. This paper mainly introduces the connotation and the basic structure of the information hypothesis of college archives management, and puts forward some ways to improve the main problems in the process of informatization.
\end{abstract}

\section{Introduction}

As one of the information resources, archives mainly cover and contain everything in scientific research, development, management, campus, school party activities such as detailed records, is the University's career, the historical development of the witness, can be used as a criterion to measure the level of University management. With the continuous development of information technology and network technology, the relationship between information technology and college archives management is becoming more and more closely. This promotes the development of information management of archives, and also brings a lot of new problems and new challenges.

\section{The connotation and constitution of college archives management in the information age}

With the continuous development and progress of the society, the archives management information has gradually become an important part of the file management. At present, the statistics and processing for digital archives, and by means of reasonable allocation of science of archival resources, so as to realize common use for all teachers and students, members of the community archives resources, so that you can use to develop and expand information file rate, so as to realize the information archives social service function. It can be said that the information construction of the archives management in Colleges and universities is in the process of paper and electronic archives management, broaden the resources and types of archives constantly on the one hand, on the other hand to use the way of continuous innovation and improvement of archives. In this way, through the application of the Internet and computing and technology, digital archives management, and further expand the application of these file management. In the process of campus digitalization, digital archives construction is very important. The use of information technology acquisition, processing, storage, application of classification of archives information, archives management in the process of improving management efficiency, maximize the sharing of resources, realize the digital collection of information, so as to make the management work further towards the digitization, standardization process.

Generally speaking, the information process of archives management mainly includes the following systems: (1) integrated wiring system. This system can meet the users quickly and easily query data needs and requirements of library workers filing process is convenient and quick, and at the same time, the development of this system to maintain performance using the system reliability, simple, extensible and other considerations; (2) network system. In the process of constructing the network system, we must follow the safety, reliability, adaptability and scalability of these four 
goals, in the process of network design, also pay attention to the universality and particularity of the archives service object, to ensure that the system is convenient and quick. (3) authentication system. In the authentication system on the choice of the modernization of the archives management system generally choose a digital certificate authentication system established by asymmetric and symmetric cryptography can be a very good security information cannot be stolen by others, and to be able to guarantee the information transmission in the process of being tampered with; (4) digital system. This system includes digital processing system, micro system, integrated management system; (5) security system. (6) archives management and monitoring system.

\section{The practical needs of college archives management in the information age}

First, the efficiency of university archives management has been improved. In the traditional file management process, managers usually take the file as an entity to manage, the management process of the workload is very large, the efficiency is very low. In the search is through manual retrieval, the staff records, and then according to the records to the warehouse to find, not only time-consuming and manpower. If the information management, file management can achieve automation and real-time sharing of information, as long as the input, can be used repeatedly, and data sharing, as long as through the network, the user can timely and fast search. On the other hand, in the process of file data statistics, we can omit the steps of manual calculation, and the information technology can make the use of the knowledge of the archives easier and easier.

Second, can continue to deepen the reform of institutions of higher learning. At present our country university system reform deeply, the university system in the unceasing change, reform has resulted in frequent flow of talent, management diversification, diversification of text files, in these problems, the information management to fully highlight the advantages. The personnel archives management as an example, with the deepening reform of personnel system in Colleges and universities are constantly changing, the terms of the contract breaking tenure calm, understanding of system reform caused the frequent flow of personnel. Some personnel agency personnel system to solve the passive situation before, will be submitted to the personnel archives service for personnel agencies specialized management, after selection of new jobs, the staff can fulfill the contract, and contract termination procedures, in this process, the process of employee personnel transfer will not be effect. Talent recruitment in Colleges and universities, only through the network platform, download information from the talent agencies to download the required professionals and basic information, and can be saved. After the implementation of information management files, information files can replace the entity management, reduce the inconvenience in the process of file query. With the continuous development of information technology, colleges and universities can directly to the file information uploaded to the Internet, in the process of management, can at any time to upload information, not only conducive to the management of archives, but also to strengthen the real-time file.

Third, paper files to be more properly protected. At present, the archives management in university is to archive collection room paper files to read, and relevant content from any relevant documents or information is the gospel. But different departments have different functions, and utilization of the archives department is very complex, for the same information, there may be a number of departments will repeat the inspection, it is not only a waste of time and manpower, affecting the efficiency of the inspection, and will accelerate the damage of paper archives. Paper record room is the most primitive and most powerful evidence material, its objectivity is beyond doubt, therefore, the protection of paper files is very important. The frequency of archives is very high, in the process, many files will repeat the query, controversial or need to review the content, the number of records read more, there are some problems in the objection, may need to repeatedly query file read, browse, query process in times of repeated disassembly in damage the velocity profile of the sharp speed. If the implementation of information management tools, you can access the file information in the database, this will reduce the archives management personnel and the paper material contact will decrease that wear, which is conducive to the preservation of paper carrier, also can prolong the life of paper material. 
Fourth, the file management information, the social value of file management will continue to improve. The biggest characteristic of information management is the openness of information. A closed file management mode limits file information dissemination and circulation, hinders the demand of people in society for archival needs, which will affect the dissemination of information, it will affect the creation of social wealth to a certain extent, resulting in China's reform and opening today, the importance of more and more small files. According to statistics, there are more than $50 \%$ people and departments in the process of circulation of information files in our country. Visible, closed file management model has been unable to meet the needs of social reform, and the party in the new era of management strategy is contrary to. The implementation of file management, file management and information technology and market development needs the combination of organic content and deepen the connotation of service, and constantly enrich and expand the service areas, realize the rational use of archival information, unearthed in the archives of the knowledge value, is conducive to the exchange of information, mutual cooperation between departments and to provide a good service for the cause of society.

\section{The path choice of college archives management in the information age}

Based on the analysis of the demand of archival information display, the paper finds out the calm of the present archival information in our country:

First, the development of the actual situation of the school file management system and model. Compared with other sectors of society, the file management of colleges and universities has its own particularity, so we should set up the file management mode in accordance with the actual situation. Such as conference records management, teacher workload management, learning management, student health standards and other aspects of management. It is precisely because of the existence of these different aspects, so for the general file management system, there are some limitations. Therefore, according to the characteristics of colleges and universities set up specifically for the file management system, the only way to achieve rule-based.

Second, strengthen the construction of archives management standards. Standardization is the premise and foundation of the modernization of archives management. In order to realize the information and network in the process of the management of archives information, we must first solve the problems in the process of the file information processing. At present, there are some problems in the management thought and management means of the University Archives Management in our country. It is precisely because of these problems, which seriously restricts the construction of our country's College Archives information. Want to continue to promote the process of information management of university archives, can make archives information resources to maximize the social benefits, university archives management departments should strengthen the construction of university archives management constantly. As an important part of the system of social archives, it is necessary to consider the management of College Archives into the whole social system. If you do not follow the rules, the process will be difficult to run. Therefore, it is necessary to establish the standards and norms of archives management, which can help the information management of University Archives and the extensive sharing of information resources.

Third, improve the content system of College archives. According to the actual situation of archives management in Colleges and universities, the content system of archives management in Colleges and universities generally consists of teaching, scientific research and management, finance, and other public facilities, in these categories can be refined out of several smaller projects. In addition, the content system of college archives management should also be diversified, such as paper writing materials, video materials, sound materials, etc.. Therefore, the archives management of archive contents in Colleges and universities should establish a scientific and standardized the contents of the file system, so as to promote the management of University Archives System of scientific development, give full play to the overall function of archives management, enhance the utilization of archives value.

Fourth, increase capital investment, strengthen the relevant hardware and software facilities 
configuration. Due to the process of information construction itself is a capital intensive projects, the need to invest a lot of money to buy the corresponding hardware and software design. In the process of information management, especially in the early stage, the construction is bound to be a high investment work. If the shortage of funds will inevitably affect the relevant software and hardware infrastructure, resulting in equipment lag, affect or even delay the process of information. At present, the construction of information management in Colleges and universities in our country, although has made certain foundation, but on the whole is still in a relatively low level, some colleges and universities is still very imperfect. Especially in some of the poor enrollment of colleges and universities, the record room and even only the most basic infrastructure, less pitiful, some universities even in the record room to cope with the state. From the view of the demand of the information management of archives management, there are still a lot of problems in the management, storage and transmission of archives management in Colleges and universities in our country. Therefore, the construction of archives information management in Colleges and universities should also increase investment in infrastructure, and accelerate the pace of overall progress.

\section{Conclusion}

With the continuous development and progress of society, information technology is developing rapidly. With the rapid development of information technology, it puts forward new requirements for the management of archives in Colleges and universities. Under the condition of knowledge economy, we all enjoy the convenience of information, but also by the informationization brings challenges, opportunities and challenges in the absence of interaction, we should grasp the development direction of University Archives management. Only by choosing the correct path of development, can we promote the continuous improvement of the management of College Archives and realize the social value of archives.

\section{Acknowledgement}

This paper was supported by the South China University of Technology Central University: Research on the problems and Countermeasures of scientific research archives management in Colleges and Universities under the background of Informationization in 2015(Project No. x2ggD2157380).

\section{Author}

Jie Lin(1981.10-), Male, Han.

Native place: Guangdong province Guangzhou, master, laboratory technician.

Work units: South China University of Technology School of public administration Main research interests: computer application, scientific research management.

Postal Address: Guangdong province Guangzhou city Tianhe District Wushan Road, building five, South China University of Technology.

Zip Code:510640

\section{References}

[1] Wang Ping. The path analysis of promoting the construction of University Archives Management Informatization in the digital age [J]. office business, 2014

[2] Jiang Cuie. Analysis on the path of the construction of archives management information system in local colleges and Universities under the background of the information age [J]. new education era electronic magazine: Teacher's edition, 2014

[3] He Caizhen. Research on the mode of university archives management service in the 
information age [J]. urban construction theory research: electronic edition, 2014, (7)

[4] Nie Xiaoming. Problems and Countermeasures of college archives management in the information age [J]. China Township Enterprise Accounting, 2013:234-235.

[5] Guan Ling. Analysis on the innovation of college archives management in the information age [J]. Journal of HeZhou University, 2013, 29:99-101.

[6] Yao Shujing. Discussion on the construction of university archives management informationization [J]. business management, 2013

[7] Zhang Limin, Cui Xiaodong. The development and utilization of College Students' Archives under the framework of knowledge management [J]. LAN, 2014:90-91. 